\title{
Segmentation of sputum smear images for detection of tuberculosis bacilli
}

\author{
Feminna Sheeba ${ }^{1 *}$, Robinson Thamburaj ${ }^{1}$, Joy Sarojini Michael², P Maqlin', Joy John Mammen² \\ From First International Science Symposium on HIV and Infectious Diseases (HIV SCIENCE 2012) \\ Chennai, India. 20-22 January 2012
}

\section{Background}

Tuberculosis (TB) is a common and lethal infectious disease, which requires accurate and early diagnosis for effective containment. Essential for the diagnosis of pulmonary infection is the detection of the bacilli through the manual microscopic examination of $\mathrm{ZN}$-stained sputum smear, which is a time-consuming, complex process necessitating at least 8-10 minutes per slide. Moreover, the quality of the detection is highly subjective to the individual who performs the analysis. These results can clearly be improved upon by using image processing techniques. The proposed work uses the segmentation techniques to automate the analysis of the sputum smear images and to detect the presence of tuberculosis bacilli in them.

\section{Methods}

This study involves assessing ZN-stained images obtained using a digital camera DFC280 attached to a compound microscope. The images acquired are 24-bit coloured tiff images. The software was developed using MATLAB R2009b. It has been deduced from the images, that the bacilli have a distinct colour and shape. The aim of the study is to identify the rod-shaped coloured bacilli, which are $1-10 \mu \mathrm{m}$ long. Colour based segmentation and property information, combined with morphological operations are used for bacilli detection.

\section{Results}

A prototype application was developed to identify these bacilli. The sensitivity, specificity, PPV and NPV of the study is $68.75 \%, 93.75 \%, 91.67 \%$ and $75 \%$ respectively.

* Correspondence: fsheeba@gmail.com

${ }^{1}$ Madras Christian College, Chennai, India

Full list of author information is available at the end of the article

\section{Conclusions}

The above study shows the potential in harnessing image analysis techniques for the detection and study of the TB bacilli. Texture analysis and identifying overlapping bacilli are required for more accurate results.

\section{Author details \\ 'Madras Christian College, Chennai, India. ${ }^{2}$ Christian Medical College, Vellore,} India.

Published: 4 May 2012

doi:10.1186/1471-2334-12-S1-014

Cite this article as: Sheeba et al:: Segmentation of sputum smear

images for detection of tuberculosis bacilli. BMC Infectious Diseases 2012 12(Suppl 1):014.
Submit your next manuscript to BioMed Central and take full advantage of:

- Convenient online submission

- Thorough peer review

- No space constraints or color figure charges

- Immediate publication on acceptance

- Inclusion in PubMed, CAS, Scopus and Google Scholar

- Research which is freely available for redistribution
C Biomed Central 